\title{
Gender differences in suicidal ideation and health-risk behaviors among high school students in Beijing, China
}

\author{
Yi-Yang Zhang ${ }^{1}$, Yuan-Ting Lei ${ }^{2}$, \\ Yi Song ${ }^{2,3}$, Ruo-Ran Lư ${ }^{4}$, Jia-Li \\ Duan $^{4}$, Judith J Prochaska ${ }^{3}$ \\ ${ }^{1}$ Peking University Third Hospital, Peking \\ University, Beijing, China \\ ${ }^{2}$ Institute of Child and Adolescent \\ Health, School of Public Health, Peking \\ University, Beijing, China \\ ${ }^{3}$ Stanford Prevention Research Center, \\ Department of Medicine, Stanford \\ University, Stanford, California, USA \\ ${ }^{4}$ Beijing Center for Disease Prevention and \\ Control, Beijing, China
}

\begin{abstract}
Background Suicide is still the leading cause of death in the 15 to 34year age group, especially for girls aging 15 to 19 -year old. In China particularly, the suicide rate of female is $60 \%$ higher than male. The gender difference on suicidal ideation and its patterns with academic, family, social and health-risk factors is unknown among adolescents in Beijing, China.
\end{abstract}

Methods A total of 33635 students in grades 7-12 in Beijing participated in the 2014 Chinese Youth Risk Behavior Surveillance. Data were stratified by gender and associations with suicidal ideation were analyzed using $\chi^{2}$ test and multivariate regression analyses. The interaction effects on suicidal ideation between gender and the related behaviors were also analyzed.

Results The prevalence of suicidal ideation was significantly higher for girls $(13.3 \%)$ than boys (10.7\%). The multivariate regression analyses indicated that high academic pressure, running away from home, feeling lonely or sad/hopeless, being bullied, fighting, and binge drinking were significantly associated with suicidal ideation in boys and girls. Factors more strongly associated with suicidal ideation in girls than boys were being in junior vs senior high school (girl vs boys: 1.24 vs NA), high academic pressure ( 2.42 vs 1.55), ever smoking (1.52 vs NA), binge drinking (1.30 vs 1.17), fighting once (1.63 vs 1.06 ) and being sad/hopeless (2.39 vs 2.04 ) and their interaction with gender were all statistically significant $(P<0.05)$. A lower likelihood of suicidal ideation was found among boys, but not girls, who had PE class two or more days per week.

Conclusions Girls showed more vulnerability to suicidal ideation than boys particularly among girls in junior school, reporting high academic pressure, smoking, binge drinking and fighting. The combinations of risk factors and differential patterns for boys and girls point to highrisk groups and potential targets for gender-specific suicide prevention.

Globally, over 800000 die of suicide every year and there is an estimation that for each individual who dies of suicide there may have been more than 20 others attempting suicide [1]. Although suicide prevalence varies among different countries and regions, the World Health Organization [2] reported that suicide was the second leading cause of death in the 15 to 29-year age group in 2014. Moreover, among girls ages 15 to 19 years old, suicide has become the leading cause of death globally. 
Although the prevalence of suicide in China decreased from 15.68 to 8.14 per 100000 between 2002 and 2011 [3], suicide remains the leading cause of death in the 15 to 34-year age group [4]. China's OneChild Policy resulted in most students being the only child in their family. Childhood suicide brings significant trauma to the family and has been recognized as a serious public health problem. By 2010, the official estimate of the annual number of deaths of only-children aged 15-30 was 76000, and the total number of Chinese families who have lost their only-children (aged over 30 were included) was approximately 1 million [5]. It is expected that this figure will reach 10 million by 2035 [6].

Many studies have reported gender differences in suicide behaviors [7-9], with an overrepresentation of females reporting suicidal ideation and exhibiting nonfatal suicidal behavior and a preponderance of males completing suicide, which is known as the "gender paradox of suicidal behavior" [10]. In developed countries, the risk of suicide is two (Western Europe) to 4-fold (USA) greater for males than females [11]. Worldwide, more than twice as many males than females aged 15 to 19 years commit suicide (4.1 per 100000 for females and 10.5 per 100000 for males) [12].

Different cultural backgrounds have different effects on suicidal behaviors. A higher completed suicide prevalence among teenage girls than boys is evident in countries such as China and India (particularly southern India) compared to the Western world [13-15]. This may in part be attributed to intergenerational and gender conflicts being more distilled and pronounced in traditional agricultural societies that are emerging into egalitarian industrial societies [16]. In China particularly, the pattern of youth suicides differs greatly to that in the West: female rate is $60 \%$ higher than male rate and rural rate is 3 -fold urban rate [17].

Suicide behaviors have been shown to be associated with a number of risk behaviors that in turn may also have immediate and long-term adverse health consequences. For example, pre-teen alcohol use initiation is associated with suicide attempts in young people and with girls at a higher risk compared with boys [18]. An analysis of data on US high school students from 1991-2011 identified five dimensions associated with suicidal thoughts and attempts; they were: violence (community or school related), substance use, sexual health, weight-related, and physical/sedentary activities [19]. The findings were recommended to promote school-based suicide prevention programs.

Most studies of youth suicidal ideation and behavior in China have been regional with small and non-representative samples. In a large representative sample, the current study sought to: (1) describe the prevalence of suicidal ideation among boys and girls in Beijing, China; (2) examine the association between suicidal ideation with family, academic and social factors and health-risk behaviors; and (3) examine gender differences in the patterns of association with suicidal ideation. The variables of interest were informed by the literature and included family structure, running away, bullying victimization and violence, mental health problems, substance use behaviors (tobacco and alcohol), and physical activities.

\section{METHODS}

\section{Design and participants}

A cross-sectional survey of 33694 middle school students from Beijing, China was conducted. Peking University's Medical Research Ethics Committee (IRB00001052-17010) approved the study procedures. Informed consent was obtained from parents and assent from the students. All of the respondents were informed that the survey would be conducted anonymously, and that their privacy would thus be respected.

A three-stage, stratified sampling method was used to obtain a representative sample of students in grades 7-12 in Beijing. First, three kinds of districts or counties were sampled according to their socioeconomic level (upper, moderate, lower). Second, the junior and senior high schools were categorized as vocational, ordinary, or key (ie,, those with good records of past educational accomplishment had priority in the assignment of teachers, equipment, and funds and the privilege of recruiting the best students). Based on probability proportional to school enrolment size, we selected 31 vocational senior high schools (grade 10-12), 36 ordinary junior high schools, 35 ordinary senior high schools, 27 key junior high schools, and 36 key senior high schools. Finally, we used a simple random sampling method to select $\mathrm{n}$ classes from each grade at each school (n depended on the average size of classes and was no less than 200 students per school). The survey was launched between April and May 2014. Participants completed the self-administered anonymous questionnaire in their classroom in the absence of school teachers 


\section{Measures}

The questionnaire was derived from the Chinese Youth Risk Behavior Surveillance (CYRBS) survey in 2014, which assesses six categories of priority health-risk behaviors contributing to the leading causes of death, disability, and social problems. The CYRBS survey [20] was adapted from the 2003 Youth Risk Behavior Surveillance survey in the United States, for which a high degree of reliability and validity has been documented previously [21-23]. The CYRBS questionnaire was reviewed by education and health experts and pilot-tested in Beijing and Jinan [24]. Suicidal ideation was assessed with the question "During the past 12 months, did you ever seriously consider attempting suicide?" Response categories were "Yes" or "No." Table 1 summarizes the academic, family, social and health-risk behavior CYRBS items of interest for the current analyses. In addition, school grade was categorized as junior or senior high school; school type as vocational, ordinary or key; and gender as boys or girls.

\section{Statistical analysis}

Of all 33694 students, 33635 (99.8\% of the sample) were included in the analyses. 59 of all 33694 records were excluded because the information of suicide ideation was missing. Of them, 13 were junior school students and 46 were from senior high school. The gender of the missing data was evenly distributed. Table 2 summarizes the sample characteristics of suicidal ideation prevalence overall and by gender. We examined the prevalence of suicidal ideation for boys and girls and the association with violence-related behaviors, substance use behaviors, physical activities, mental health problems and running away from home by $\chi^{2}$ test. Those variables significantly related with suicide ideation in univariate analysis were included in multivariate logistic regression model and analyzed as co variables by the method of Backward wald. Multivariate logistic regression analyses were stratified by gender, and school type was adjusted in all models. For boys, multivariate logistic regression analyses were limited to the 91.6\% (15428/16850) boys for which complete information was available, and 8.4\% (1422/16850) records were excluded because one or more independent variables were missing, and for girls, 93.7\% (15733/16785) records were included and 6.3\% (1052/16785) were excluded due to missing information of one or more independent variables. We examined adjusted OR and 95\% confidence intervals (CI) to assess the significance of the associations. The percent relative standard error (PRSE) test was performed for testing the reliability of regression coefficients. PRSE $<25 \%$ could be considered as a reliable estimation. [25] Besides, interac-

Table 1. Characteristics of independent variables

\begin{tabular}{|c|c|c|}
\hline Construct & Description OF QUESTIONS & Responses \\
\hline Academic pressure & $\begin{array}{l}\text { In the past } 12 \text { months, how often did you feel unhappy because of } \\
\text { stress/pressure from school? }\end{array}$ & $\begin{array}{l}\text { "none" ="low", "rarely or sometimes" = "average", "of- } \\
\text { ten or always" = "high" }\end{array}$ \\
\hline School achievement & How do you think your performance compares with your classmates? & "above average", "average", "below average" "not sure \\
\hline Family structure & Who do you live with at home? & "both parents" vs other \\
\hline Smoking & Have you ever tried cigarette smoking, even one or two puffs & "Yes" or "No" \\
\hline $\begin{array}{l}\text { Binge drinking last } \\
30 \text { days }\end{array}$ & $\begin{array}{l}\text { During the past } 30 \text { days, on how many days did you have five or more } \\
\text { drinks of alcohol in a row that is, within a couple of hours? }\end{array}$ & "0" or " $1-30 "$ \\
\hline $\begin{array}{l}\text { Physical fighting past } \\
12 \text { months }\end{array}$ & $\begin{array}{l}\text { During the past } 12 \text { months, how many times were you in a physical } \\
\text { fight }\end{array}$ & "0", "1" or "2 or more times" \\
\hline PE classes & $\begin{array}{l}\text { In an average week when you are in school, on how many days do you } \\
\text { go to physical education (PE) classes }\end{array}$ & "0 or 1 day" and "More days" \\
\hline Exercising & $\begin{array}{l}\text { During the past } 7 \text { days, on how many days were you physically active } \\
\text { for a total of at least } 60 \mathrm{~min} \text { per day? }\end{array}$ & "0-2 days" and "More days" \\
\hline $\begin{array}{l}\text { Considered running } \\
\text { away from home in } \\
\text { last } 12 \text { months }\end{array}$ & $\begin{array}{l}\text { During the past } 12 \text { months, did you ever seriously consider running } \\
\text { away from home that is, leaving your home for } 24 \mathrm{~h} \text { or more without } \\
\text { your parents' permission? }\end{array}$ & "Yes" or "No" \\
\hline $\begin{array}{l}\text { Ran away from home } \\
\text { in last } 12 \text { months }\end{array}$ & $\begin{array}{l}\text { During the past } 12 \text { months, did you ever attempt to run away from } \\
\text { home (for } 24 \text { h or more without your parents' permission)? }\end{array}$ & "Yes" or "No" \\
\hline Victim of bullying & $\begin{array}{l}\text { During the last } 12 \text { months have you ever been (a) 'hit, kicked, pushed, } \\
\text { shoved around, or locked indoors?' (b) 'Made fun of or insulted?' (c) } \\
\text { 'Excluded intentionally or prevented from participating?' (d) 'Made fun } \\
\text { of with gender jokes, comments or gestures?'; 'blackmailed for money?' } \\
\text { or (f) 'bullied in some other way?' }\end{array}$ & $\begin{array}{l}\text { Victims who reported at least one victimization ex- } \\
\text { perience in the last } 12 \text { months with a frequency of } \\
\text { "often" }\end{array}$ \\
\hline Feeling lonely & During the past 12 months, did you ever feel lonely & "Never", "rarely or sometimes" and "often or always" \\
\hline Feeling sad/hopeless & $\begin{array}{l}\text { During the past } 12 \text { months, did you ever feel so sad or hopeless almost } \\
\text { every day for } 2 \text { weeks or more in a row that you stopped doing some } \\
\text { usual activities }\end{array}$ & "Yes" or "No" \\
\hline
\end{tabular}


Table 2. Characteristics of suicidal ideation prevalence by genders

\begin{tabular}{|c|c|c|c|c|c|c|c|c|}
\hline \multirow[t]{2}{*}{ Variabies } & & \multirow[t]{2}{*}{ Тотац/Count (\%) } & \multicolumn{3}{|c|}{ Boys } & \multicolumn{3}{|c|}{ Giris } \\
\hline & & & $\mathrm{N}$ & Count (\%) & P-value* & $\mathrm{N}$ & Count (\%) & P-value* \\
\hline \multirow[t]{2}{*}{ Grade } & Junior (grade 7-9) & $14844(11.7)$ & 7708 & $747(9.7)$ & \multirow{2}{*}{$<0.001$} & 7136 & $992(13.9)$ & \multirow{2}{*}{0.042} \\
\hline & Senior (grade 10-12) & $18549(12.2)$ & 8996 & $1041(11.6)$ & & 9553 & $1225(12.8)$ & \\
\hline \multirow[t]{3}{*}{ School type } & Key & $12391(12.2)$ & 5946 & $659(11.1)$ & \multirow{3}{*}{0.200} & 6445 & $848(13.2)$ & \multirow{3}{*}{0.815} \\
\hline & Ordinary & $13197(11.7)$ & 6625 & $679(10.2)$ & & 6572 & $861(13.1)$ & \\
\hline & Vocational & $5202(12.4)$ & 2776 & $313(11.3)$ & & 426 & $330(13.6)$ & \\
\hline \multirow[t]{2}{*}{ Family structure } & Both parents & $28121(11.1)$ & 13983 & $1372(9.8)$ & \multirow{2}{*}{$<0.001$} & 14138 & $1746(12.3)$ & \multirow{2}{*}{$<0.001$} \\
\hline & Others & $5514(16.6)$ & 2867 & $431(15.0)$ & & 2647 & $485(18.3)$ & \\
\hline \multirow[t]{3}{*}{ Academic pressure } & Low & $6258(6.6)$ & 3969 & $267(6.7)$ & \multirow{3}{*}{$<0.001$} & 2289 & $1456.3)$ & \multirow{3}{*}{$<0.001$} \\
\hline & Average & $18568(8.3)$ & 8578 & $651(7.6)$ & & 9990 & $894(8.9)$ & \\
\hline & High & $8788(23.6)$ & 4293 & $885(20.6)$ & & 4495 & $1191(26.5)$ & \\
\hline \multirow[t]{4}{*}{ Academic achievement } & Above average & $12389(10.5)$ & 5741 & $547(9.5)$ & \multirow{4}{*}{$<0.001$} & 6648 & $756(11.4)$ & \multirow{4}{*}{$<0.001$} \\
\hline & Average & $10315(10.6)$ & 4792 & $415(8.7)$ & & 5523 & $674(12.2)$ & \\
\hline & Below average & $8637(15.3)$ & 4954 & $655(13.2)$ & & 3683 & $665(18.1)$ & \\
\hline & Not sure & $1638(14.7)$ & 962 & $141(14.7)$ & & 676 & $100(14.8)$ & \\
\hline \multirow[t]{2}{*}{ Ever smoking } & Yes & $7686(19.1)$ & 4989 & $764(15.3)$ & \multirow{2}{*}{$<0.001$} & 2697 & $706(26.2)$ & \multirow{2}{*}{$<0.001$} \\
\hline & No & $25414(9.9)$ & 11554 & $1007(8.7)$ & & 13860 & $1504(10.9)$ & \\
\hline \multirow[t]{2}{*}{ Binge drinking last $30 \mathrm{~d}$} & Yes & $3855(22.7)$ & 2612 & $497(19.0)$ & \multirow{2}{*}{$<0.001$} & 1243 & $377(30.3)$ & \multirow{2}{*}{$<0.001$} \\
\hline & No & $29693(10.6)$ & 14183 & $1303(9.2)$ & & 15510 & $1851(11.9)$ & \\
\hline Fighting & Never & $26953(9.9)$ & 11759 & $944(8.0)$ & & 15194 & $1739(11.4)$ & \\
\hline & Once & $3064(16.5)$ & 2206 & $266(12.1)$ & $<0.001$ & 858 & $241(28.1)$ & $<0.001$ \\
\hline & Twice or more & $3587(23.3)$ & 2869 & $590(20.6)$ & & 718 & $247(34.4)$ & \\
\hline PE classes & 0 or 1 per week & $2200(15.3)$ & 1135 & $181(15.9)$ & & 1065 & $156(14.6)$ & 0173 \\
\hline & $\geq 2$ per week & $31309(11.7)$ & 15647 & $1611(10.3)$ & $<0.001$ & 15662 & $2065(13.2)$ & 0.173 \\
\hline Exercising $\geq 60 \mathrm{~min}$ & 0-2 days per week & $10568(13.0)$ & 4206 & $493(11.7)$ & 0013 & 6362 & $879(13.8)$ & 0116 \\
\hline & $>2$ days per week & $23055(11.5)$ & 12637 & $1309(10.4)$ & 0.013 & 10418 & $1351(13.0)$ & 0.116 \\
\hline Considering running & Yes & $9686(27.2)$ & 4377 & $1140(26.0)$ & & 5309 & $1492(28.1)$ & \\
\hline away from home & No & $23448(5.7)$ & 12187 & $631(5.2)$ & $<0.001$ & 11261 & $707(6.3)$ & $<0.001$ \\
\hline Running away from home & Yes & $1969(37.6)$ & 1187 & $425(35.8)$ & (1) & 782 & $315(40.3)$ & נחOח \\
\hline & No & $31500(10.3)$ & 15584 & $1360(8.7)$ & $<0.001$ & 15916 & $1887(11.9)$ & $<0.001$ \\
\hline Victim of bullying & Yes & $3902(25.6)$ & 2732 & $611(22.4)$ & 1 & 1170 & $389(33.2)$ & 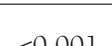 \\
\hline & No & $29580(10.1)$ & 14034 & $1177(8.4)$ & $<0.001$ & 15546 & $1825(11.7)$ & $<0.001$ \\
\hline Feeling lonely & Never & $11048(5.0)$ & 6253 & $304(4.9)$ & & 4795 & $252(5.3)$ & \\
\hline & Sometimes or seldom & $18100(11.0)$ & 8396 & $859(10.2)$ & $<0.001$ & 9704 & $1138(11.7)$ & $<0.001$ \\
\hline & Often or always & $4461(33.1)$ & 2188 & $638(29.2)$ & & 2273 & $840(37.0)$ & \\
\hline Being sad/hopeless & Yes & $4537(30.3)$ & 2489 & $654(26.3)$ & & 2048 & $725(35.4)$ & \\
\hline & No & $29044(9.1)$ & 14327 & $1141(8.0)$ & $<0.001$ & 14717 & $1503(10.2)$ & $<0.001$ \\
\hline Total & & $33635(12.0)$ & 16850 & $1803(10.7)$ & & 16785 & $2231(13.3)$ & \\
\hline
\end{tabular}

PE - physical exercise

* $P$-value for intra-variable difference.

tion analysis was used to test the between-groups difference of gender. All analyses were conducted using SPSS 19.0 (IBM, Armonk, New York, USA). Two-sided $P$ values of $<0.05$ were considered significant.

\section{RESULTS}

\section{Prevalence of suicidal ideation}

As shown in Table 2, overall, $12.0 \%$ reported suicidal ideation in the past year, higher in girls (13.3\%) than boys $(10.7 \%)\left(\chi^{2}=53.50, P<0.001\right)$. Suicidal ideation was more common among students living without both parents (16.6\%), who reported high academic pressure (23.6\%), who had tried smoking (19.1\%), who reported binge drinking (22.7\%), who had fought more than once (23.3\%), who considered $(27.2 \%)$ or attempted to run away from home (37.6\%), who had been a victim of bullying $(25.6 \%)$, and who reported often or always feeling lonely (33.1\%), or sad/hopeless (30.3\%). 


\section{Univariate associations between suicidal ideation and risk factors by gender}

Table 2 summarizes the prevalence of suicidal ideation overall and comparisons between different levels of sociodemographic factors and health-risk behaviors by gender. Suicidal ideation was associated with almost all health risk behaviors and sociodemographic variables other than school type. By grade level and gender, boys in senior high school and girls in junior high school were more likely to report suicidal ideation. The students living with both parents were less likely to report suicidal ideation. Among both genders, suicidal ideation was associated with high academic pressure, lower average academic achievement, smoking, binge drinking, fighting more than once, considering or attempting running away from home, being bullied, often or always feeling lonely and feeling sad/hopeless. In general, the associations with suicidal ideation were stronger for girls than for boys.

\section{Multivariate associations between suicidal ideation and risk factors}

According to the multivariate logistic regression, patterns of the association between suicidal ideation and risk factors were different by gender. For example, being in junior high school, ever smoking, and fighting one time were associated with suicidal ideation for girls but not boys. Junior girls were at a $24 \%$ higher risk of having suicidal ideation than senior girls ( $A O R=1.24,95 \% C I=1.11-1.38$ ). Girls who ever smoked were at a $52 \%$ higher risk of having suicidal ideation than girls who did not smoke $(A O R=1.52$, 95\% CI =1.33-1.72). Girls who had fighting experience were more likely to have suicidal ideation. Among boys only, having 2 or more PE classes per week was associated with less suicidal ideation $(A O R=0.75$, 95\% CI=0.61-0.92) and girls showed no association between PE classes and less suicidal ideation. However, there were still a set of behavioral risk factors associated with suicidal ideation both in boys and girls, such as family structure, academic pressure, binge drinking, fighting, considering or attempting running away from home, victim of bullying, feeling lonely and being sad/hopeless. Moreover, almost all significant variables presented reliability by PRSE (Table 3 ).

Table 3. Multivariate logistic regression analysis between suicidal ideation, grade, family structure and health-risk behaviors by gender among Chinese students (AOR, 95\% CI)

\begin{tabular}{|c|c|c|c|c|c|}
\hline VARIABIES & Boys* & PRSE & Giris* & PRSE & $\begin{array}{l}\text { INTERACTION TERM } \\
\text { P-VALUE }\end{array}$ \\
\hline Grade (junior vs senior) & - & & $1.24(1.11,1.38) \dagger$ & 26.0 & 0.002 \\
\hline \multicolumn{6}{|l|}{ Family structure: } \\
\hline Both parents & 1.00 & & 1.00 & & \\
\hline Others & $1.31(1.14,1.50) \ddagger$ & 26.0 & $1.17(1.03,1.34) \dagger$ & 42.2 & 0.271 \\
\hline \multicolumn{6}{|l|}{ Academic pressure: } \\
\hline Low & 1.00 & & 1.00 & & \\
\hline Average & $0.95(0.79,1.12)$ & 156.1 & $1.19(0.97,1.47)$ & 60.5 & 0.051 \\
\hline High & $1.55(1.30,1.85) \ddagger$ & 20.8 & $2.42(1.95,3.00) \ddagger$ & 12.4 & $<0.001$ \\
\hline \multicolumn{6}{|l|}{ Academic achievement: } \\
\hline Above average & 1.00 & & - & & \\
\hline Average & $0.88(0.75,1.02)$ & 59.5 & - & & 0.253 \\
\hline Below average & $1.04(0.90,1.19)$ & 194.6 & - & & 0.459 \\
\hline Not sure & $1.39(1.10,1.75) \dagger$ & 36.4 & - & & 0.071 \\
\hline Smoking & - & & $1.52(1.33,1.72) \dagger$ & 15.9 & $<0.001$ \\
\hline Binge drinking (yes) & $1.17(1.01,1.34) \dagger$ & 46.8 & $1.30(1.09,1.54) \dagger$ & 33.6 & $<0.001$ \\
\hline \multicolumn{6}{|l|}{ Fighting: } \\
\hline Never & 1.00 & & 1.00 & & \\
\hline Once & $1.06(0.90,1.25)$ & 150.9 & $1.63(1.35,1.97) \ddagger$ & 19.8 & $<0.001$ \\
\hline Twice or more & $1.42(1.23,1.62) \ddagger$ & 20.2 & $1.57(1.28,1.92) \ddagger$ & 23.4 & 0.046 \\
\hline$\geq 2$ PE classes per week & $0.75(0.61,0.92) \dagger$ & 36.5 & - & & $<0.001$ \\
\hline Exercising over $60 \mathrm{~min}>2$ days per week & - & & - & & - \\
\hline Considering running away from home & $3.70(3.27,4.19) \ddagger$ & 4.8 & $3.15(2.82,3.52) \ddagger$ & 4.9 & 0.770 \\
\hline Running away from home & $1.87(1.59,2.20) \ddagger$ & 13.4 & $1.72(1.42,2.07) \dagger$ & 17.8 & 0.735 \\
\hline Victim of bullying & $1.49(1.31,1.71) \ddagger$ & 17.0 & $1.54(1.31,1.82) \ddagger$ & 19.1 & 0.226 \\
\hline \multicolumn{6}{|l|}{ Feeling lonely: } \\
\hline Never & 1.00 & & 1.00 & & \\
\hline Sometimes or seldom & $1.49(1.27,1.75) \ddagger$ & 20.3 & $1.53(1.30,1.80)$ † & 19.5 & 0.199 \\
\hline Often or always & $3.00(2.50,3.59) \ddagger$ & 8.5 & $3.40(2.83,4.10)$ † & 7.8 & 0.008 \\
\hline Being sad/hopeless & $2.04(1.79,2.33) \ddagger$ & 9.4 & $2.39(2.10,2.72)$ † & 7.5 & 0.018 \\
\hline
\end{tabular}

PRSE - percent relative standard error, AOR - adjusted odds ratio, CI - confidence interval, PE - physical exercise

*Adjusted for school type in all models - designates not entered into the model.

$\uparrow \mathrm{P}<0.05$.

$¥ \mathrm{P}<0.001$. 


\section{Interaction effects on suicidal ideation between gender and behavioral risk factors}

As shown in Table 3, girls showed stronger associations with suicidal ideation (with higher AORs) for junior high school (1.24 vs NA), high academic pressure (2.42 vs 1.55), and almost all health risk behaviors, such as smoking (1.52 vs NA), binge drinking (1.30 vs 1.17), fighting once (1.63 vs 1.06), feeling lonely often or always (3.40 vs 3.00), and being sad/hopeless (2.39 vs 2.04), and their interaction with gender were all statistically significant $(P<0.05)$, but considered running away from home was the exception, which was a stronger correlate for boys (3.70 vs 3.15).

\section{DISCUSSION}

In this study, $12.0 \%$ of students in Beijing reported suicidal ideation in the past year, which is lower than the Chinese average for youth (17.99\%) from 2002-2012 [26]. Our study is consistent with previous researches in Australia and American $[7,27,28]$ that girls had a higher risk of suicidal ideation than boys. However, girls from Australian secondary schools showed much higher risk of suicide ideation than boys (21.8\% vs 8.3\%) [7]. In our study, girls in junior high school were more likely than boys and senior high school girls to report suicidal ideation, which may relate to the early-maturing of female students. Ge et al. found [29] that early-maturing girls represented the group with the highest rate of depressive symptoms and had more possibility of suicide ideation.

Residing with two parents was associated with a lower likelihood of suicidal ideation. Xing et al. reported [30] that for many children with divorced parents or parents working out of town for extended periods, social resources within the families are reduced. Garnefski and Diekstra [31] observed that the lowest risk of suicide attempts was in the intact family structure compared with others. They found that students from one parent and stepparent families reported more emotional problems, ie, lower self-esteem, more symptoms of anxiety and loneliness, more depressed mood and more suicidal thoughts than children from intact families, especially for girls [31]. In the present study, 18.3\% of girls in non-intact families reported suicidal ideation.

Our findings showed that academic pressure and achievement showed strong association with suicidal ideation for boys and girls. In China, college entrance and senior high school entrance examinations (named "gaokao" and "zhongkao") decide whether students can enter a key university or senior high school. Emphasizing academic success and very high academic expectations have become common concerns of Chinese parents [32,33]. Consequently, Chinese high school students spend a great deal of time on school assignments and in preparation for examinations, which may contribute to mental health disorders and suicidal behaviors $[33,34]$. In the current study, girls not only showed higher academic pressure but also were more likely to report suicidal ideation at the same pressure or achievement levels as boys. According to Ge et al.'s theory [29], girls were more likely than boys to encounter vulnerability when confronted with stress. This may be due to gender differences in family and social roles, social status, and problem-solving [35]. Moreover, Chinese adolescents are more suffering from the academic pressure than those in Western countries because of the different cultural background, and the evidence of migrant studies also showed that Asian American had a higher prevalence of suicide plan or attempts than other races due to the academic pressure in most cases [36].

Prior researches $[18,37]$ have found that in young people and adults, smoking is among the strongest predictors of suicidal behavior [38] in the Western. But in the present study, smoking was only associated with suicidal ideation for girls. Moreover, binge drinking and fighting experience were more strongly associated with suicidal ideation for girls than boys in this study. In the context of Chinese traditional culture, smoking, binge drinking and fighting among girls are disapproved of by adults and society [20]. Girls having had these experiences or behaviors may be considered rebellious and may experience alienation. Prohibition of alcohol, tobacco and campus violence are imperative for school management and may provide a protective influence on suicidal behavior.

Both boys and girls with behavioral risk factors like considering or attempting running away from home and being bullied were at higher risk of suicidal ideation in our study, which is consistent with previous studies $[39,40]$. Being bullied can be a significant traumatic stress, and associated with many negative effects [41-44]. The present findings indicated that about $11.7 \%$ students ever experienced bullying, higher in boys (16.3\%) than girls (7\%). While girls were less likely to be bullied, girls who were bullied showed a much higher prevalence of suicidal ideation than boys bullied (33.2\% vs 22.4\%). Bannink et al. reported that traditional as well as cyber bullying victimization is associated with an increasing risk of 
mental health problems among girls [43]. The gender difference in strength of association between bullying and suicidal ideation may be partly explained by differences in the types of bullying to which boys and girls are exposed. Previous studies have found that girls often experience more relational victimization (eg, spreading rumors or social isolation), and that relational victimization has a greater impact on mental health problems than overt, physical victimization, which is more often experienced by boys [4547]. Our findings stress the importance of programs aiming at reducing bullying behaviors in schools, both for girls and boys.

Many studies show that depression is an essential mediator between suicide and health risk factors [44]. In this study, boys reported a slightly higher prevalence of depressive symptoms, eg, feeling so sad or hopeless almost every day for 2 weeks or more in a row that you stopped doing some usual activities; however, girls with depressive symptoms had the highest suicidal ideation prevalence. These girls may need more psychological assistance and supports in daily life. We found that having two or more PE classes per week was associated with a lower likelihood of suicidal ideation among boys, but not girls. Exercising over 60 minutes more than twice a week showed a weak association with boys' suicidal ideation. Research [4850] has consistently demonstrated that exercise is associated with lower levels of clinical and subclinical depression in cross-sectional and experimental studies. Further, exercise has been found to have a direct negative association with suicide risk and also an indirect relation with suicide risk through depression symptom and sleep quality [51]. That is, higher levels of exercise were associated with lower depressive symptoms and better sleep quality, which were in turn was associated with less suicide risk. Promoting exercise before, during (though daily PE), and after school could be a simple and realizable intervention with broad physical and mental population health benefits [52-54].

\section{Limitations}

Overall, the findings demonstrated consistent and strong associations between health-risk behaviors and suicidal ideation for boys and girls in Beijing junior and senior high schools. Several limitations ought to be considered when interpreting the findings. First, because of the cross-sectional study design, we could only demonstrate associations and not causal paths between suicide and health risk factors. Second, the traditional view that suicidal ideation and depression represent unhealthy psychological status may have biased reporting and resulted in an underestimate of suicidal ideation prevalence. Third, due to the highly developed socioeconomic status of Beijing, not all presenting findings are suitable for extrapolating to other underdeveloped regions in China, and more researches about these regions are needed.

\section{CONCLUSIONS}

Academic pressure and achievement, family structure, substance use, fighting or being bullied, runaway behaviors and mental health problems are associated with suicidal ideation for boys and girls. Girls were more likely to report suicidal ideation than boys. By gender and grade, girls in junior high school were the most likely to report suicidal ideation. With a great deal of emotional investment in one's offspring, magnified by China's single-child policy, efforts to address suicidal ideation and prevent suicide seem imperative for Chinese society and school administers. School health providers and parents ought to be mindful of the signs and correlates of suicidal ideation. Regular physical education and health education on mental health supported by campus psychologists might help to prevent suicide ideation and mental health problems in Chinese youth.

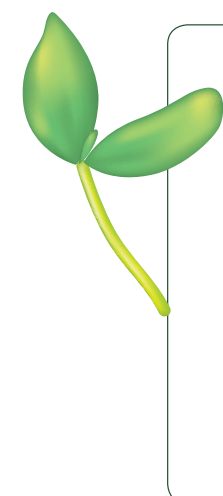

Acknowledgements: We thank all investigators and officials from Beijing CDCs for their contributions to data collection. We also thank the teachers and students at schools that participated in this study for their cooperation, and thank M.S. Dong-mei Luo for her contribution on the statistical works.

Funding: The present study was supported by grants from the National Natural Science Foundation of China (81302442) and the China Scholarship Council (201606015038).

Authorship contributions: YZ and YS conceived and designed the study. YZ carried out the initial analyses and prepared the first draft of the manuscript. YS, JJP and YL critically reviewed and revised the manuscript. YS, JLD and RRL conducted the research and collected the data. All authors read and approved the final manuscript.

Competing interests: The authors have completed the Unified Competing Interest form at www.icmje.org/ coi_disclosure.pdf (available on request from the corresponding author) and declare no conflict of interest. 
1 Fleischmann A, De Leo D. The World Health Organization's report on suicide: a fundamental step in worldwide suicide prevention. Crisis. 2014;35:289-91. Medline:25297514 doi:10.1027/0227-5910/a000293

2 Shuchman M. Suicide report indicates shift at WHO. CMAJ. 2014;186:E532. Medline:25225220 doi:10.1503/cmaj.1094897

3 Zhang J, Sun L, Liu Y, Zhang J. The change in suicide rates between 2002 and 2011 in China. Suicide Life Threat Behav. 2014;44:560-8. Medline:24690079 doi:10.1111/sltb.12090

4 Wang SY, Li YH, Chi GB, Xiao SY, Ozanne-Smith J, Stevenson M, et al. Injury-related fatalities in China: an under-recognised public-health problem. Lancet. 2008;372:1765-73. Medline:18930527 doi:10.1016/S0140-6736(08)61367-7

5 Health CMo. 2010 China Yearbook of Health. Beijing Union Medical College Press. 2010.

6 Huang J. Losing their only child. Global Times Online 25 June 2012.

7 Delfabbro PH, Winefield HR, Winefield AH. Life-time and current suicide-ideation in Australian secondary school students: Socio-demographic, health and psychological predictors. J Affect Disord. 2013;151:514-24. Medline:23871389 doi:10.1016/j.jad.2013.06.036

8 Beautrais AL. Gender issues in youth suicidal behaviour. Emerg Med (Fremantle). 2002;14:35-42. Medline:11993833 doi:10.1046/j.1442-2026.2002.00283.x

9 Canetto SS, Sakinofsky I. The gender paradox in suicide. Suicide Life Threat Behav. 1998;28:1-23. Medline:9560163

10 Schrijvers DL, Bollen J, Sabbe BG. The gender paradox in suicidal behavior and its impact on the suicidal process. J Affect Disord. 2012;138:19-26. Medline:21529962 doi:10.1016/j.jad.2011.03.050

11 Hawton K. Sex and suicide. Gender differences in suicidal behaviour. Br J Psychiatry. 2000;177:484-5. Medline:11102320 doi:10.1192/bjp.177.6.484

12 McLoughlin AB, Gould MS, Malone KM. Global trends in teenage suicide: 2003-2014. QJM. 2015;108:765-80. Medline:25638789 doi:10.1093/qjmed/hcv026

13 Wasserman D, Jiang GX. Global suicide rates among young people aged 15-19. World Psychiatry. 2005;4:114-20. Medline: 16633527

14 Patel V, Ramasundarahettige C, Vijayakumar L, Thakur JS, Gajalakshmi V, Gururaj G, et al. Suicide mortality in India: a nationally representative survey. Lancet. 2012;379:2343-51. Medline:22726517 doi:10.1016/S0140-6736(12)60606-0

15 Aaron R, Joseph A, Abraham S, Muliyil J, George K, Prasad J, et al. Suicides in young people in rural southern India. Lancet. 2004;363:1117-8. Medline:15064031 doi:10.1016/S0140-6736(04)15896-0

16 Kim WJ, Singh T. Trends and dynamics of youth suicides in developing countries. Lancet. 2004;363:1090-1. Medline:15064023 doi:10.1016/S0140-6736(04)15931-X

17 Li XY, Phillips MR, Zhang YP, Xu D, Yang GH. Risk factors for suicide in China's youth: a case-control study. Psychol Med. 2008;38:397-406. Medline:17825127 doi:10.1017/\$0033291707001407

18 Swahn MH, Bossarte RM, Ashby JS, Meyers J. Pre-teen alcohol use initiation and suicide attempts among middle and high school students: findings from the 2006 Georgia Student Health Survey. Addict Behav. 2010;35:452-8. Medline:20089362 doi:10.1016/j.addbeh.2009.12.017

19 Lowry R, Crosby AE, Brener ND, Kann L. Suicidal thoughts and attempts among U.S. High school students: trends and associated health-risk behaviors, 1991-2011. J Adolesc Health. 2014;54:100-8. Medline:24035267 doi:10.1016/j. jadohealth.2013.07.024

20 Song Y, Ji CY, Agardh A. Sexual coercion and health-risk behaviors among urban Chinese high school students. Glob Health Action. 2014;7:24418. Medline:24836445 doi:10.3402/gha.v7.24418

21 Brener ND, Kann L, McManus T, Kinchen SA, Sundberg EC, Ross JG. Reliability of the 1999 youth risk behavior survey questionnaire. J Adolesc Health. 2002;31:336-42. Medline:12359379 doi:10.1016/S1054-139X(02)00339-7

22 Brener ND, Kann L, Kinchen SA, Grunbaum JA, Whalen L, Eaton D, et al. Methodology of the youth risk behavior surveillance system. MMWR Recomm Rep. 2004;53:1-13. Medline:15385915

23 Brener ND, Collins JL, Kann L, Warren CW, Williams BI. Reliability of the Youth Risk Behavior Survey Questionnaire. Am J Epidemiol. 1995;141:575-80. Medline:7900725 doi:10.1093/oxfordjournals.aje.a117473

24 Xing Y, Ji C, Zhang L. Relationship of binge drinking and other health-compromising behaviors among urban adolescents in China. J Adolesc Health. 2006;39:495-500. Medline:16982383 doi:10.1016/j.jadohealth.2006.03.014

25 Silesh GW. The relative standard error as an easy index for checking the reliability of regression coefficients. Discussion paper. 2015.

26 Chang WW, Yao YS, Yuan H, Chen BF, Liang YL, Chen Y, et al. Prevalence of suicide ideation among middle school students in China: a systematic analysis of studies between 2000 and 2012. Zhonghua Liu Xing Bing Xue Za Zhi. 2013;34:515-9. Medline:24016446

27 Jiang Y, Perry DK, Hesser JE. Adolescent suicide and health risk behaviors: Rhode Island's 2007 Youth Risk Behavior Survey. Am J Prev Med. 2010;38:551-5. Medline:20409502 doi:10.1016/j.amepre.2010.01.019

28 Fried LE, Williams S, Cabral H, Hacker K. Differences in risk factors for suicide attempts among 9th and 11th grade youth: a longitudinal perspective. J Sch Nurs. 2013;29:113-22. Medline:23008186 doi:10.1177/1059840512461010

29 Ge X, Conger RD, Elder GHJ. Pubertal transition, stressful life events, and the emergence of gender differences in adolescent depressive symptoms. Dev Psychol. 2001;37:404-17. Medline:11370915 doi:10.1037/0012-1649.37.3.404

30 Xing XY, Tao FB, Wan YH, Xing C, Qi XY, Hao JH, et al. Family factors associated with suicide attempts among Chinese adolescent students: a national cross-sectional survey. J Adolesc Health. 2010;46:592-9. Medline:20472217 doi:10.1016/j. jadohealth.2009.12.006 
31 Garnefski N, Diekstra RF. Adolescents from one parent, stepparent and intact families: emotional problems and suicide attempts. J Adolesc. 1997;20:201-8. Medline:9104655 doi:10.1006/jado.1996.0077

32 Goyette KXY. Educational expectations of Asian American youths determinants and ethnic differences. Sociol Educ. 1999;72:22-36. doi:10.2307/2673184

33 Liu X, Tein JY. Life events, psychopathology, and suicidal behavior in Chinese adolescents. J Affect Disord. 2005;86:195203. Medline:15935239 doi:10.1016/j.jad.2005.01.016

34 Unger JBLY, Johnson CA, Gong J, Chen X, Li C. Stressful life events among adolescents in Wuhan, China. Int J Behav Med. 2001;8:1-18. doi:10.1207/S153275581JBM0801_01

35 Yao YS, Chang WW, Jin YL, Chen Y, He LP, Zhang L. Life satisfaction, coping, self-esteem and suicide ideation in Chinese adolescents: a school-based study. Child Care Health Dev. 2014;40:747-52. Medline:24824894 doi:10.1111/cch.12142

36 Anderson LM, Lowry LS, Wuensch KL. Racial differences in adolescents' answering questions about suicide. Death Stud. 2015;39:600-4. Medline:26083790 doi:10.1080/07481187.2015.1047058

37 Gart R, Kelly S. How Illegal Drug Use, Alcohol Use, Tobacco Use, and Depressive Symptoms Affect Adolescent Suicidal Ideation: A Secondary Analysis of the 2011 Youth Risk Behavior Survey. Issues Ment Health Nurs. 2015;36:614-20. Medline:26379135 doi:10.3109/01612840.2015.1015697

38 Poorolajal J, Darvishi N. Smoking and Suicide: A Meta-Analysis. PLoS One. 2016;11:e0156348. Medline:27391330 doi:10.1371/journal.pone.0156348

39 Matchinda B. The impact of home background on the decision of children to run away: The case of Yaounde city street children in Cameroon. Child Abuse Negl. 1999;23:245-55. Medline:10219943 doi:10.1016/S0145-2134(98)00130-6

$40 \mathrm{Ek}$ CA, Steelman LC. Becoming a runaway from the accounts of youthful runners. Youth Soc. 1988;19:334-57. doi:10.1177/0044118X88019003006

41 Wang H, Zhou X, Lu C, Wu J, Deng X, Hong L, et al. Adolescent bullying involvement and psychosocial aspects of family and school life: a cross-sectional study from Guangdong Province in China. PLoS One. 2012;7:e38619. Medline:22815693 doi:10.1371/journal.pone.0038619

42 Hong L, Wu H, Li P, Xu Y, Gao X. Bullying, depression, and suicidal ideation among adolescents in the Fujian Province of China. Medicine (Baltimore). 2016;95:e2530. Medline:26844460 doi:10.1097/MD.0000000000002530

43 Bannink R, Broeren S, van de Looij-Jansen PM, de Waart FG, Raat H. Cyber and traditional bullying victimization as a risk factor for mental health problems and suicidal ideation in adolescents. PLoS One. 2014;9:e94026. Medline:24718563 doi:10.1371/journal.pone.0094026

44 Sampasa-Kanyinga H, Roumeliotis P, Xu H. Associations between cyberbullying and school bullying victimization and suicidal ideation, plans and attempts among Canadian schoolchildren. PLoS One. 2014;9:e102145. Medline:25076490 doi:10.1371/journal.pone.0102145

45 Crick NR, Bigbee MA. Relational and overt forms of peer victimization: a multiinformant approach. J Consult Clin Psychol. 1998;66:337-47. Medline:9583337 doi:10.1037/0022-006X.66.2.337

46 Cullerton-Sen CCN. Understanding the effects of physical and relational victimization: the utility of multiple perspectives in predicting social-emotional adjustment. School Psych Rev. 2005;34:147-60.

47 Baldry AC. The impact of direct and indirect bullying on the mental and physical health of Italian youngsters. Aggress Behav. 2004;30:343-55. doi:10.1002/ab.20043

48 Conn VS. Depressive symptom outcomes of physical activity interventions: meta-analysis findings. Ann Behav Med. 2010;39:128-38. Medline:20422333 doi:10.1007/s12160-010-9172-x

49 De Moor MH, Beem AL, Stubbe JH, Boomsma DI, De Geus EJ. Regular exercise, anxiety, depression and personality: a population-based study. Prev Med. 2006;42:273-9. Medline:16439008 doi:10.1016/j.ypmed.2005.12.002

50 Hoffman BM, Babyak MA, Craighead WE, Sherwood A, Doraiswamy PM, Coons MJ, et al. Exercise and pharmacotherapy in patients with major depression: one-year follow-up of the SMILE study. Psychosom Med. 2011;73:127-33. Medline:21148807 doi:10.1097/PSY.0b013e31820433a5

51 Davidson CL, Babson KA, Bonn-Miller MO, Souter T, Vannoy S. The impact of exercise on suicide risk: examining pathways through depression, PTSD, and sleep in an inpatient sample of veterans. Suicide Life Threat Behav. 2013;43:27989. Medline:23901428 doi:10.1111/sltb.12014

52 Fleischmann A, Bertolote JM, Wasserman D, De Leo D, Bolhari J, Botega NJ, et al. Effectiveness of brief intervention and contact for suicide attempters: a randomized controlled trial in five countries. Bull World Health Organ. 2008;86:7039. Medline:18797646 doi:10.2471/BLT.07.046995

53 Linehan MM, Comtois KA, Murray AM, Brown MZ, Gallop RJ, Heard HL, et al. Two-year randomized controlled trial and follow-up of dialectical behavior therapy vs therapy by experts for suicidal behaviors and borderline personality disorder. Arch Gen Psychiatry. 2006;63:757-66. Medline:16818865 doi:10.1001/archpsyc.63.7.757

54 Brown GK, Ten Have T, Henriques GR, Xie SX, Hollander JE, Beck AT. Cognitive therapy for the prevention of suicide attempts: a randomized controlled trial. JAMA. 2005;294:563-70. Medline:16077050 doi:10.1001/jama.294.5.563 